\title{
Avaliação da eficiência da propagação de Alcantarea imperialis (Bromeliaceae) cultivada in vitro e ex vitro ${ }^{1}$
}

Evaluating the effectiveness of the propagation of Alcantarea imperialis (Bromeliaceae) cultivated in vitro and ex vitro

\author{
Elisa Mitsuko Aoyama, ${ }^{2,6}$ Leonardo de Melo Versieux, ${ }^{3}$ Catarina Carvalho Nievola ${ }^{4}$ \\ \& Solange Cristina Mazzoni-Viveiros ${ }^{5}$
}

\begin{abstract}
Resumo
O cultivo in vitro de bromélias tem sido considerado uma técnica eficiente para aperfeiçoar a sua produção. Contudo, não existem relatos que comparem a eficiência dos métodos de propagação in vitro e ex vitro da bromélia-imperial Alcantarea imperialis (Carrière) Harms utilizada no paisagismo e considerada ameaçada de extinção devido ao extrativismo ilegal. O cultivo in vitro surge como uma boa alternativa para se preservar a diversidade genética dessa espécie polimórfica, assegurando a matéria-prima para a evolução contemporânea ocorrer. O objetivo deste trabalho foi comparar o crescimento de plantas de A. imperialis, cultivadas in vitro e ex vitro, a partir de sementes, estabelecendo o período ideal de transferência para aclimatação. As sementes foram submetidas à desinfestação superficial antes de serem transferidas para as condições de cultivo (meio de cultura ou substrato de casca de Pinus sp.). Após períodos pré-estabelecidos, plântulas cultivadas in vitro foram transferidas para condições ex vitro (aclimatação). As plântulas provenientes do cultivo in vitro apresentaram maiores valores para todos os parâmetros analisados em relação àquelas cultivadas ex vitro. Os dados demonstraram que a aclimatação de plântulas mantidas in vitro por 2, 4 e 6 meses apresentaram maior crescimento, em comparação àquelas aclimatadas após terem sido cultivadas por mais tempo in vitro. Os resultados deste trabalho mostram a eficiência do método de cultivo in vitro, indicando o tempo ideal para a permanência das plântulas nos meios nutritivos, estabelecendo importante relação custo-benefício para sua produção.
\end{abstract}

Palavras-chave: aclimatação, bromélia-imperial, conservação ex situ, micropropagação, sementes.

\begin{abstract}
The in vitro cultivation of bromeliads has been considered an effective technique to improve its production. However, there are no studies that compare the efficiency of the methods of in vitro propagation versus ex vitro for the Brazilian giant bromeliad Alcantarea imperialis (Carrière) Harms used in landscaping and considered to be endangered due to illegal extraction. The in vitro culture appears as a good alternative to preserve the genetic diversity of this polymorphic species, assuring that the raw material for the contemporary evolution will be available. The aim of this study was to compare the growth of plants of $A$. imperialis in vitro and ex vitro obtained from seed, establishing the ideal transfer period. The seeds were disinfected before being transferred to culture conditions (culture medium or Pinus sp. bark substrate). After the pre-established growing time, in vitro plants were transferred to ex vitro (acclimatization). Plants from in vitro cultures showed higher values for all measured parameters compared to those grown ex vitro. The data showed that the acclimation of plants cultivated in vitro for 2, 4, and 6 months showed better growth compared to those acclimated after being cultured in vitro for longer time. These results show the efficiency of the in vitro culture method, indicating the ideal time for the maintenance of the plants in nutrient media, providing important cost-benefit ratio for production. Key-words: acclimatization, Brazilian giant bromeliad, ex situ conservation, micropropagation, seeds.
\end{abstract}

\footnotetext{
'Parte da tese de Doutorado da primeira autora, Programa de Pós-Graduação em Biodiversidade Vegetal e Meio Ambiente do Instituto de Botânica, São Paulo, SP.

${ }^{2}$ Universidade Federal do Espírito Santo, Centro Universitário Norte do Espírito Santo, Depto. Ciências Agrárias e Biológicas, Rod. BR 101 Norte km 60 s/n, 29932-540, São Mateus, ES.

${ }^{3}$ Universidade Federal do Rio Grande do Norte, Depto. Botânica, Ecologia e Zoologia, 59072-900, Natal, RN.

${ }^{4}$ Instituto de Botânica, Núcleo de Pesquisa em Plantas Ornamentais, C.P. 68041, 04045-972, São Paulo.

${ }^{5}$ Instituto de Botânica, Núcleo de Pesquisa em Anatomia, C.P. 68041, 04045-972, São Paulo.

${ }^{6}$ Autor para correspondência: elisaoyama@yahoo.com.br
} 


\section{Introdução}

A produção de bromélias em escala comercial é atividade viável e tem sido bastante explorada no Brasil, seguindo os passos de outros países, como os Estados Unidos, a Holanda e a Bélgica. A qualidade das plântulas assim obtidas é superior àquela de extrações criminosas em florestas (Melo 1996), fato este que, unido ao preço acessível, coloca as plantas cultivadas em grande vantagem no mercado. Dentre as técnicas de produção das espécies vegetais, a propagação por meio de técnicas de cultivo in vitro apresenta inúmeras vantagens, se comparada à produção em sistemas convencionais em estufa (Debergh \& Maene 1981; Pierik 1987; Debergh 1994; Fay 1994; Engelmann 1997; Thorpe \& Harry 1997; Hartmann et al. 2002; Carneiro \& Mansur 2004), sendo um importante método de propagação para espécies ameaçadas de extinção e/ou ornamentais (Engelmann 1991; Fay 1994; Sarasan et al. 2006).

Dentre as espécies de bromélia de interesse ornamental, destaca-se a Alcantarea imperialis (Carrière) Harms, conhecida popularmente como bromélia-imperial ou bromélia-gigante (Versieux \& Wanderley 2009). Esta espécie está incluída na Lista Oficial das Espécies da Flora Brasileira Ameaçadas de Extinção (MMA 2008). A broméliaimperial caracteriza-se morfologicamente por ser uma herbácea perene de grande porte $(>140 \mathrm{~cm})$, heliófila, rupícola ou saxícola, formando grandes populações sobre paredões rochosos principalmente na Serra dos Órgãos (Rio de Janeiro), embora também por vezes na Serra da Mantiqueira (Minas Gerais) (Barbará et al. 2007, Monteiro \& Forzza 2008, Versieux 2009). Suas folhas e brácteas apresentam variações da cor verde ao vermelhoescuro ou vinoso. Algumas dessas variações foram chamadas de color morphs por Barbará et al. (2007). Eventualmente, podem ser variegadas. Apresenta inflorescência densa, com 2-3 metros de altura, ramificada, piramidal, com pedúnculo ereto, excedendo as folhas. O período de floração é de cerca de 5 meses, concentrando-se no verão; as flores são vistosas, visitadas por insetos e beijaflores e polinizadas por morcegos (Martinelli 1997). Essa espécie é amplamente utilizada em projetos paisagísticos não só no Brasil como em outros países. Isso justifica a preocupação com a sua propagação para atender a tal demanda, de modo a evitar que indivíduos adultos sejam retirados de seu habitat, onde o crescimento tende a ser lento (E.M. Aoyama, dados não publicados).

Para a conservação desta espécie, estabelecer protocolos para seu cultivo ex situ é extremamente importante: as populações de A. imperialis são naturalmente fragmentadas e geneticamente isoladas entre os distintos afloramentos em que ocorrem, mantendo elevada diversidade genética (Barbará et al. 2007, 2008, 2009). Sendo assim, o cultivo ex situ surge como uma estratégia para se preservar esta diversidade interpopulacional e atender à exigência atual da biologia da conservação, que apregoa que não basta preservar a espécie ou alguns espécimes. É necessário manter a diversidade genética interpopulacional, matéria-prima do processo de evolução contemporânea (Moritz 2002; Stockwell et al. 2003).

Alcantarea imperialis está incluída na Lista Oficial das Espécies da Flora Brasileira Ameaçadas de Extinção (MMA 2008), conforme consta no Anexo II, considerada com "Dados Deficientes", o que reforça a necessidade de se estudar todos os aspectos biológicos desta espécie. Apesar da conservação in situ ser uma das ações mais propostas pelos ambientalistas, nem sempre isto é viável, sendo necessárias estratégias de conservação ex situ, onde indivíduos de determinada espécie são mantidos em cultivo sob supervisão. Dentre essas técnicas, destaca-se o cultivo in vitro (Carneiro \& Mansur 2004; Sarasan et al. 2006), seguido do processo de aclimatação ex vitro, com diversas aplicações que podem auxiliar não apenas nas etapas de propagação, como também na restauração de ambientes degradados e no fornecimento de material vegetal para outras áreas de pesquisa, como a química de produtos naturais (Pence 2011).

Embora plântulas mantidas in vitro tenham o crescimento favorecido, não há relatos sobre a eficiência dessa técnica em comparação com a produção convencional de bromélias em estufa, a partir de semeadura, ou assexuadamente através de propagação vegetativa. Adicionalmente, não foram encontrados trabalhos que visem avaliar o tempo mínimo de permanência das plântulas nos frascos de cultivo antes de serem submetidas à etapa de aclimatação, de modo a reduzir os gastos com a manutenção das culturas.

Este trabalho se propôs, assim, a comparar o crescimento de plântulas de A. imperialis, 
cultivadas in vitro e ex vitro, a partir da germinação de sementes, de modo a verificar qual sistema de cultivo é mais adequado à maior produção de mudas, informando as possíveis razões das diferenças. Tendo em vista que a aclimatação é uma importante etapa para produção de plântulas via micropropagação, objetivou-se também avaliar qual o tempo mínimo de permanência das culturas in vitro, a fim de se obter sucesso no processo de aclimatação.

\section{Material e Métodos}

O trabalho foi conduzido no Laboratório de Cultura de Tecidos do Núcleo de Pesquisas em Plantas Ornamentais, localizado no Instituto de Botânica, São Paulo, Brasil.

As sementes foram retiradas de frutos maduros de três indivíduos de $A$. imperialis cultivados no Instituto de Botânica (Fig. 1a) que estavam armazenadas por cerca de 3 meses a $10^{\circ} \mathrm{C}$. Estas foram testadas quanto à viabilidade, sendo que atingiram $80 \%$ de germinação. Após a remoção dos apêndices plumosos, as sementes (Fig. 1b) foram desinfestadas superficialmente com solução de etanol a $70 \%$ por cinco minutos, seguida por imersão em solução de benomil $1 \%$ por cinco minutos, e posteriormente em solução de hipoclorito de sódio comercial 4\% adicionada de algumas gotas de Tween 20, sendo mantidas durante 60 minutos. Após essa etapa, as sementes foram enxaguadas três vezes com água destilada esterilizada. Este procedimento de desinfestação é comumente utilizado para sementes que têm apêndices plumosos como relatado para outras espécies (Aranda-Perez \& Martinelli 2009; Pedroso et al. 2010).

\section{Estabelecimento do cultivo in vitro}

Foram preparados 100 frascos de cultura com $40 \mathrm{ml}$ de meio de cultura MS (Murashige \& Skoog 1962) modificado para conter metade da concentração recomendada dos macronutrientes e a original dos micronutrientes, suplementação com $100 \mathrm{mg} \mathrm{l}^{-1}$ de mio-inositol, $0,1 \mathrm{ml} \mathrm{l}^{-1} \mathrm{de}$ tiamina, $30 \mathrm{~g} \mathrm{l}^{-1}$ de sacarose, $5 \mathrm{~g} \mathrm{l}^{-1}$ de ágar e $\mathrm{pH}$ ajustado para 5,8 antes de ser esterilizado em autoclave a $121^{\circ} \mathrm{C}$ por 15 minutos. Sob fluxo laminar, 15 sementes já desinfectadas foram inoculadas em cada frasco réplica. $\mathrm{O}$ experimento foi conduzido por 12 meses em sala de cultura com fotoperíodo de $12 \mathrm{~h}$, irradiância de $30 \mu \mathrm{mol} \mathrm{m}^{-1} \mathrm{~s}^{-1}$ e temperatura controlada (26 $\pm 2^{\circ} \mathrm{C}$ ) (Fig. 1c).

Após 1, 2, 4, 6, 8, 10 e 12 meses de experimento, 50 plântulas para cada período foram avaliadas quanto ao comprimento e número de raízes, comprimento da maior folha, número de folhas sadias (consideradas aquelas totalmente verdes) e senescentes, massas fresca e seca.

\section{Estabelecimento do cultivo ex vitro}

Para o experimento ex vitro foram utilizadas oito caixas tipo "gerbox" forradas com papel de filtro umedecido com água destilada, recebendo cada uma delas 100 sementes Após 30 dias, as plântulas obtidas foram transferidas para bandejas de isopor contendo casca de Pinus sp. compostada como substrato. Para evitar a perda excessiva de umidade, as bandejas foram envolvidas por saco plástico transparente (Fig. 1d), ficando expostas à irradiância de aproximadamente $30 \mu \mathrm{mol} \mathrm{m} \mathrm{m}^{-1} \mathrm{~s}^{-1}$. As plântulas foram semanalmente adubadas com solução de MS sem sacarose, sendo aplicados 50 $\mathrm{ml}$ de solução por aspersão.

Os ensaios de aclimatação foram mantidos na mesma sala de cultura descrita anteriormente, e após 1, 2, 4, 6, 8, 10 e 12 meses de experimento, 50 plântulas para cada período foram avaliadas quanto ao comprimento e número de raízes, comprimento da maior folha, número de folhas sadias e senescentes, massas fresca e seca.

\section{Aclimatação}

Após 1, 2, 4, 6, 8, 10 e 12 meses de cultivo in vitro, 100 plântulas de cada período foram transferidas para as condições ex vitro e permaneceram por dois meses nas mesmas condições de luminosidade, temperatura e adubação acima descritas, e ao final dessa etapa foram avaliadas quanto ao comprimento e o número das raízes, comprimento da maior folha, número de folhas sadias e senescentes, massas fresca e seca.

Para os cálculos de incremento de crescimento após o período de aclimatação foi utilizada a média dos dados analisados das plântulas cultivadas nas condições in vitro em todos os períodos, subtraídos das médias para os mesmos parâmetros das plântulas após a aclimatação. $\mathrm{O}$ valor resultante foi multiplicado por 100 e dividido pelo valor da média das plântulas in vitro. 

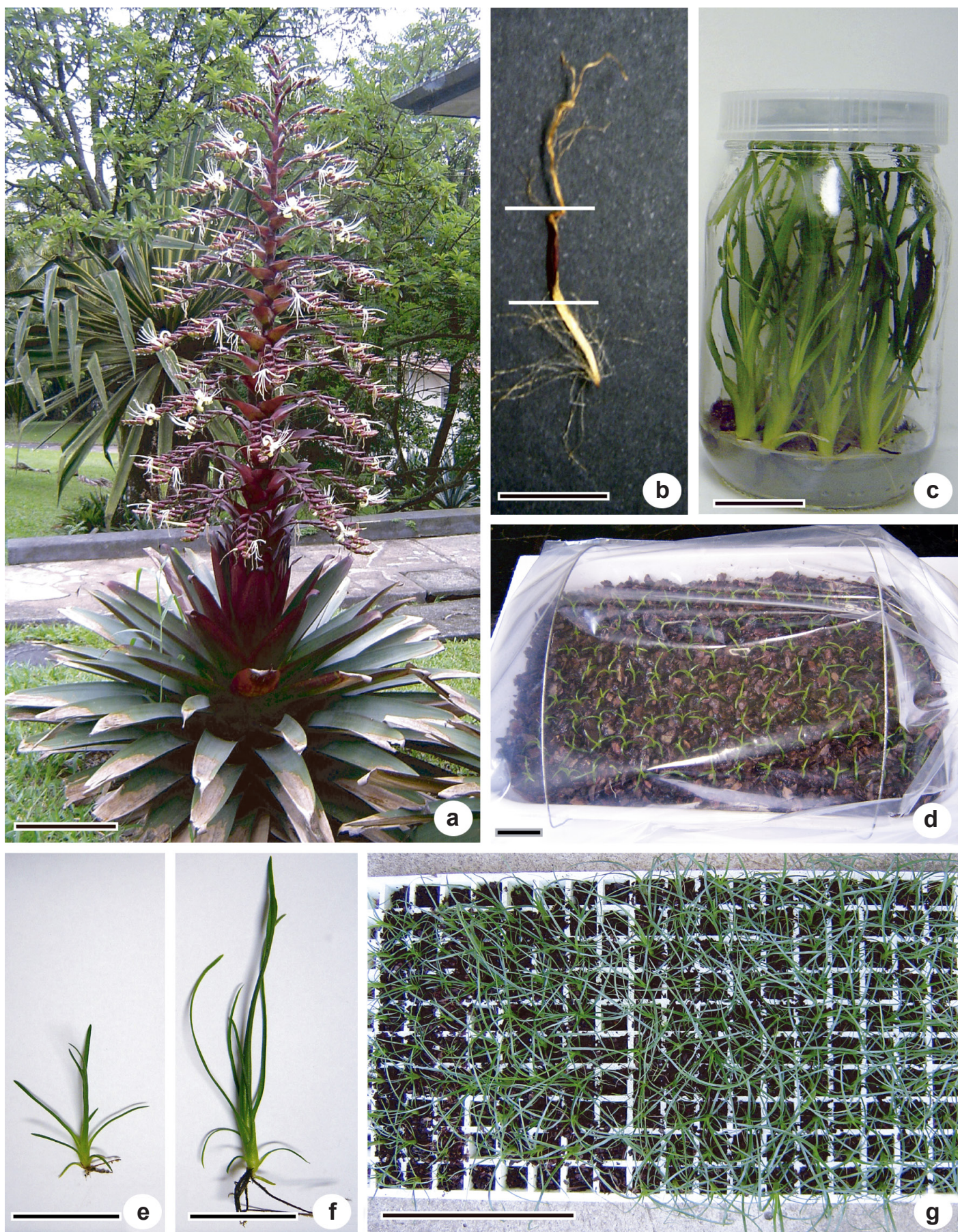

Figura 1 - Alcantarea imperialis - a. aspecto da planta em floração; b. semente com apêndices plumosos; os traços indicam a região onde foram retirados os apêndices; c. frasco de cultivo in vitro com plantas jovens (6 meses); d. bandeja com plantas em substrato de casca de Pinus envolvida por saco plástico (1 mês); e. planta cultivada por 6 meses em condições ex vitro; f. planta cultivada por 6 meses em cultivo in vitro; g. bandeja com plantas após o período de aclimatação ( 8 meses). Barra $=50 \mathrm{~cm}(\mathrm{a}), 1 \mathrm{~cm}(\mathrm{~b}-\mathrm{f}), 10 \mathrm{~cm}(\mathrm{~g})$.

Figure 1-Alcantarea imperialis $-a$. flowering plant; $b$. seeds with feathery appendage, dashes indicate the region where the appendages were removed; c. in vitro cultivation vessel with young plants (6 months); d. trays with plants in Pinus bark as substrate covered with transparent plastic (1 month); e. plant derived from ex vitro culture after six months of growth; f. plant derived from in vitro culture after six months of growth; g. trays with plants after the acclimatization (8 months). Bars $=50 \mathrm{~cm}(\mathrm{a}), 1 \mathrm{~cm}(\mathrm{~b}-\mathrm{f}), 10 \mathrm{~cm}(\mathrm{~g})$. 
Análise estatística

Para a análise dos dados foi utilizada a estatística descritiva, calculando-se o desvio padrão entre as médias obtidas. Os dados foram submetidos ao teste de normalidade, à análise de variância (ANOVA) e ao teste Tukey (Dias \& Barros 2009), utilizando-se o pacote estatístico BioEstat 5.0.

\section{Resultados e Discussão}

Os resultados obtidos, apresentados nas Figuras 1 a 4, e nas Tabelas 1 e 2, demonstram que a micropropagação in vitro a partir de sementes de Alcantarea imperialis propiciou condições de maior desenvolvimento das plântulas em comparação àquelas cultivadas ex vitro (Figs. 1e-f). Adicionalmente, indicou o tempo adequado para iniciar a aclimatação, contribuindo para a diminuição de custos de manutenção das culturas, confirmando os dados encontrados em trabalhos que utilizaram técnicas de micropropagação com outras espécies de bromélias ameaçadas ou endêmicas visando, também, à sua produção comercial e, consequentemente, sua conservação (Mercier \& Kerbauy 1995; Mercier \& Nievola 2003; Carneiro \& Mansur 2004).

Em relação à parte aérea, observou-se que as diferenças entre os tratamentos in vitro e ex vitro iniciaram-se a partir do segundo mês de cultivo, permanecendo até o final do experimento (Fig. 2a). Houve maior crescimento das plântulas mantidas in vitro em relação àquelas cultivadas em bandejas, mesmo constatando que em ambos os tratamentos a germinação ocorreu simultaneamente. Observouse que a partir do quarto mês de cultivo a diferença no comprimento da maior folha foi aumentando até que as plântulas mantidas in vitro atingissem cerca do dobro das cultivadas ex vitro (Fig. 2a). Contudo, em relação ao número de folhas, observou-se que apenas após 6 meses as plântulas cultivadas in vitro eram significativamente maiores que naquelas cultivadas ex vitro (Fig. 2b). Entretanto, após 8,10 e 12 meses, o número de folhas não foi significativamente diferente entre os tratamentos (12 folhas em média). Nota-se que a partir do $6^{\circ}$ mês ocorre a morte das folhas, de modo crescente até o $12^{\circ}$ mês, sendo que no tratamento in vitro foram observadas nove folhas senescentes, em média, aos 12 meses (Fig. 3). Já na condição ex vitro apenas 3 folhas senesceram nesse mesmo tempo de cultivo (Fig. 3). Esses resultados podem indicar o momento que as plântulas atingiram o crescimento intenso, notadamente para o cultivo in vitro, havendo necessidade da realocação dos nutrientes das folhas mais velhas para as mais jovens, pela escassez de algum elemento mineral móvel no corpo vegetal, como por exemplo, os íons de nitrogênio.

O melhor desempenho das plântulas in vitro pode ser devido à presença de sacarose no meio de cultura. É reconhecido o importante papel da sacarose como componente do meio de cultura, servindo como fonte de carbono e energia para as plântulas, necessária para compensar a taxa fotossintética que, nessas condições, é prejudicada em função da restrição das trocas gasosas (Torres et al. 1998). Contudo, alguns autores atribuem como função dos carboidratos a influência sobre o desenvolvimento de órgãos (Calvete et al. 2002). Segundo Kozai (1991), a presença de carboidratos no meio de cultura é importante para o desenvolvimento das raízes, para a multiplicação dos brotos e para o aumento da altura da plântula. Além disso, a presença de sacarose propicia o fornecimento de esqueletos carbônicos necessários à incorporação dos nutrientes (Buchanan et al. 2002; Taiz \& Zeiger 2009).

Embora não tenham sido encontrados trabalhos que comparem o crescimento de bromélias cultivadas in vitro com as cultivadas em estufa, algumas espécies de monocotiledôneas avaliadas apresentaram tais diferenças. Segundo Reuther (1988), em estudo com cultivares de Spathiphyllum floribundum (Linden and André) N.E.Br. cv. 'Mauna Loa', notou-se maiores valores de massa seca nas plântulas mantidas em condições ex vitro, devido ao pouco desenvolvimento dos tecidos foliares in vitro, principalmente os de sustentação, resultando em folhas mais delgadas.

Os resultados de acúmulo de massa corroboram aqueles apresentados em relação ao comprimento das folhas, indicando ter havido um maior crescimento nas plântulas mantidas in vitro em comparação ao outro tratamento (Fig. 2a, c-d). Os dados de massas fresca e seca apresentaram as maiores diferenças entre os valores nos períodos de cultivo in vitro a partir do sexto mês, quando comparados com os valores das plântulas de mesma idade cultivadas em condições ex vitro (Figs. 2c-d). 

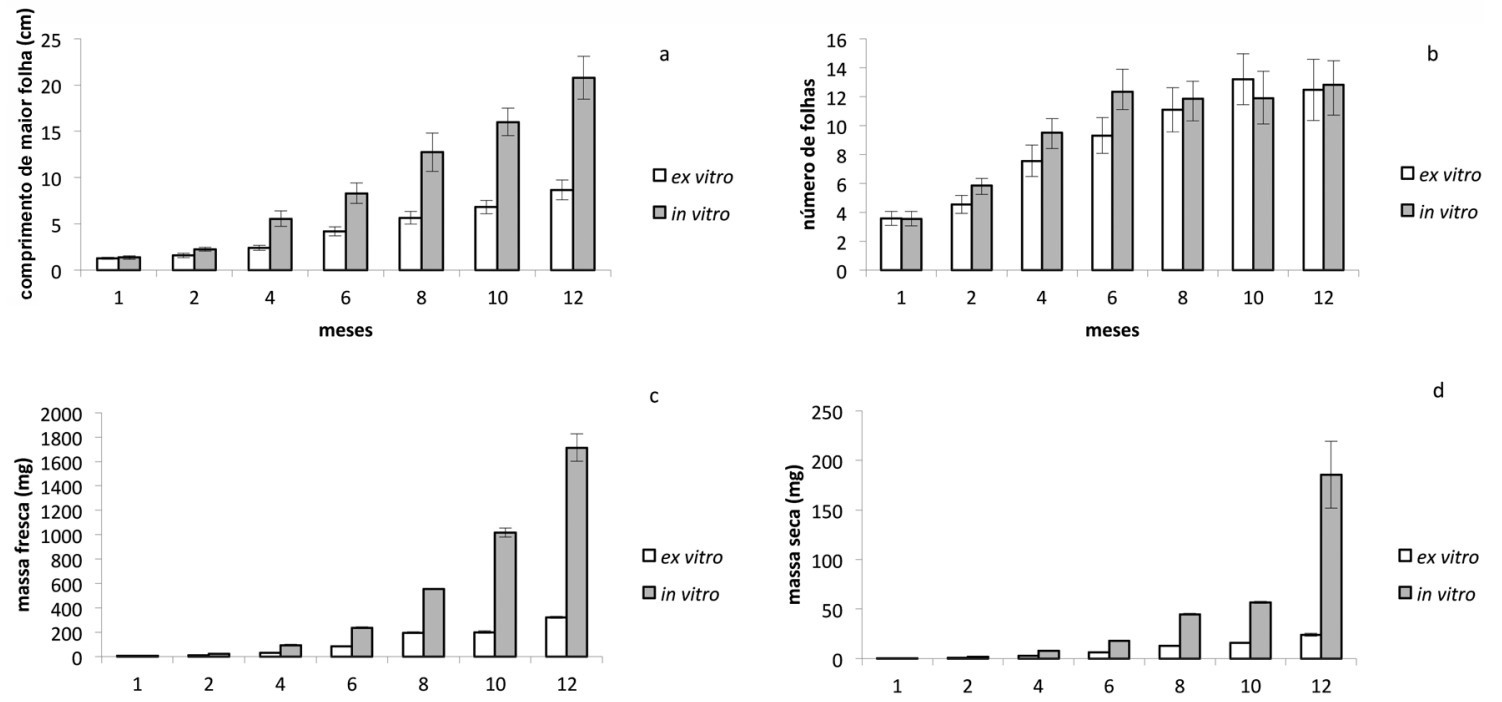

Figura 2 - Crescimento da parte aérea de plantas de Alcantarea imperialis cultivadas in vitro e ex vitro por 1 , 2, 4, 6, 8, 10 e 12 meses - a. comprimento de maior folha ( $\mathrm{cm})$; b. número de folhas; c. massa fresca (mg); d. massa seca $(\mathrm{mg})$. Os valores representam a média e as barras indicam o desvio padrão $(n=50)$.

Figure 2-Aerial portion growth of Alcantarea imperialis cultivated in vitro for 1, 2, 4, 6, 8, 10 and 12 months - a. length (cm); b. number of leaves; c. fresh mass (mg); d. dry mass $(\mathrm{mg})$. The values represented the average and the bars indicated the standard deviations $(n=50)$.

Tabela 1 - Crescimento da parte aérea de plantas de Alcantarea imperialis cultivadas in vitro por 1, 2, 4, 6, 8, 10 e 12 meses e submetidas à aclimatação por 2 meses.

Table 1 - Aerial portion growth of Alcantarea imperialis cultivated in vitro for 1, 2, 4, 6, 8, 10 and 12 months and submitted to acclimatization for 2 months.

\begin{tabular}{cccccc}
\hline $\begin{array}{c}\text { Período in vitro } \\
\text { (meses) }\end{array}$ & $\begin{array}{c}\text { Comprimento } \\
\mathbf{( \% )}\end{array}$ & $\begin{array}{c}\text { Número de } \\
\text { folhas } \mathbf{( \% )}\end{array}$ & $\begin{array}{c}\text { Número de folhas } \\
\text { senescentes } \mathbf{( \% )}\end{array}$ & $\begin{array}{c}\text { Massa fresca } \\
\mathbf{( \% )}\end{array}$ & $\begin{array}{c}\text { Massa seca } \\
\mathbf{( \% )}\end{array}$ \\
\hline 1 & 131,88 & 67,98 & $*$ & 367,23 & 257,79 \\
2 & 145,42 & 84,93 & $*$ & 575,22 & 507,77 \\
4 & 35,14 & 13,26 & $*$ & 81,65 & 54,94 \\
6 & 110,79 & $*$ & 155,70 & 326,98 & 267,36 \\
8 & 72,12 & $*$ & $*$ & 176,42 & 158,57 \\
10 & 12,68 & $*$ & $*$ & 51,43 & 93,73 \\
12 & 15,93 & $*$ & 2,09 & 64,09 & 8,72 \\
\hline
\end{tabular}

(*) tende a zero

Técnicas de cultivo in vitro apresentam vantagens sobre as de propagação convencionais (Fay 1994; Engelmann 1997; Thorpe \& Harry 1997; Kozai et al. 1997) em razão da disponibilidade de água, dos nutrientes, do tipo de substrato e das condições livres de patógenos. Contudo, as análises dos dados das raízes das plântulas podem também explicar o maior crescimento da parte aérea. A presença e o grau de desenvolvimento das raízes são fatores limitantes para o processo de aclimatação, já que as plântulas irão depender da capacidade de absorção para sobreviver a essa nova condição. 
Tabela 2 - Índice de sobrevivência e crescimento das raízes de plantas de Alcantarea imperialis cultivadas in vitro por 1, 2, 4, 6, 8, 10 e 12 meses e submetidas à aclimatação por 2 meses.

Table 2 - Survival rate and growth of Alcantarea imperialis roots cultivated in vitro for 1, 2, 4, 6, 8, 10 and 12 months and submitted to acclimatization for 2 months.

\begin{tabular}{cccccc}
\hline $\begin{array}{c}\text { Período in vitro } \\
(\mathbf{m e s e s})\end{array}$ & $\begin{array}{c}\text { Sobrevivência } \\
\mathbf{( \% )}\end{array}$ & $\begin{array}{c}\text { Comprimento } \\
\mathbf{( \% )}\end{array}$ & $\begin{array}{c}\text { Número } \\
\mathbf{( \% )}\end{array}$ & $\begin{array}{c}\text { Massa fresca } \\
\mathbf{( \% )}\end{array}$ & $\begin{array}{c}\text { Massa seca } \\
\mathbf{( \% )}\end{array}$ \\
\hline 1 & 100 & 62,80 & 46,46 & 139,12 & 213,76 \\
2 & 99 & 45,98 & 104,79 & 226,34 & 298,42 \\
4 & 96 & 112,16 & 41,70 & $*$ & 40,19 \\
6 & 100 & 27,40 & 62,04 & 19,56 & 58,67 \\
8 & 100 & 36,18 & 52,13 & 2,31 & 2,58 \\
10 & 100 & 4,59 & 26,19 & $*$ & 5,06 \\
12 & 100 & 4,40 & 23,58 & 9,28 & 7,17 \\
\hline
\end{tabular}

$(*)$ tende a zero

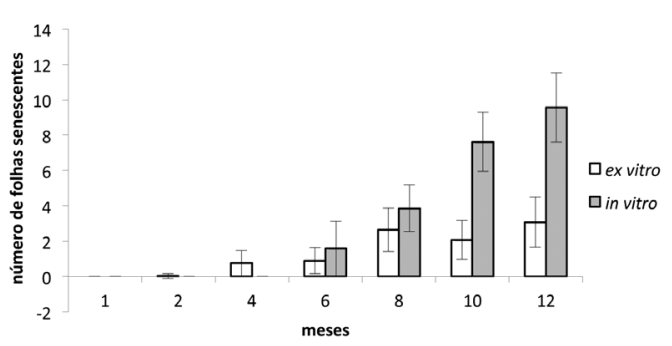

Figura 3 - Número de folhas senescentes de plantas de Alcantarea imperialis cultivadas in vitro e ex vitro por 1, 2, 4, 6, 8, 10 e 12 meses. Os valores representam a média e as barras indicam o desvio padrão $(n=50)$. Figure 3 - Number of senescent leaves of Alcantarea imperialis cultivated in vitro and ex vitro for 1, 2, 4, 6, 8, 10 and 12 months. The values represented the average and the bars indicated the standard deviations $(n=50)$.

A análise dos dados biométricos das raízes mostrou que logo a partir do primeiro mês de cultivo houve diferença significativa entre os tratamentos para os parâmetros comprimento e acúmulo de massa (Fig. 4a-d). O aumento de ambos ocorreu ao longo do tempo, sendo que as maiores diferenças foram observadas a partir do $6^{\circ}$ mês (cerca de cinco vezes maior para as plântulas mantidas in vitro), à semelhança do observado para a parte aérea (Figs. 2a e 4a). O crescimento radical das plântulas cultivadas em bandejas não foi tão intenso quanto ao das plântulas mantidas no meio nutritivo in vitro. Enquanto que as plântulas provenientes do tratamento ex vitro aumentaram 1,4 vezes em média ao longo do tempo, aquelas do cultivo in vitro duplicaram o crescimento radical a cada dois meses em média, sendo que ao comparar-se o comprimento de raízes de plântulas com 4 meses com aquelas de 6 meses, observou-se um aumento em até três vezes no comprimento radical (Fig. 4a). A mesma tendência foi observada para o número de raízes, com aumento de duas vezes (Fig. 4a). O número de raízes (Fig. 4b) nas plântulas cultivadas in vitro teve um aumento mais expressivo a partir do $6^{\circ}$ mês de cultivo, sendo que as plântulas do cultivo in vitro apresentaram o dobro do número de raízes das plântulas com a mesma idade e cultivadas em condições ex vitro. Nas plântulas com 12 meses in vitro o número médio de raízes foi três vezes maior ao das plântulas com a mesma idade cultivada $e x$ vitro (Fig. 4b).

Os dados de massa para as raízes, tanto fresca quanto seca (Fig. 4c-d), apresentaram aumento em todos os períodos analisados. As plântulas ex vitro apresentaram valores menores de massa fresca das raízes quando comparadas com as plântulas do cultivo in vitro, sendo essa diferença mais evidente a partir do $6^{\circ}$ mês (Fig. 4c). Os dados de massa seca das raízes das plântulas do cultivo ex vitro só foram maiores naquelas com 1 mês de idade. Nos demais períodos, as plântulas do cultivo in vitro apresentaram maiores valores de massa seca das raízes (Fig. 4d) que aquelas mantidas ex vitro. 
Com base nos dados observados neste trabalho foi possível verificar que as plântulas que se desenvolveram nas condições in vitro apresentaram maior crescimento, tanto das raízes como da parte aérea, porém não apresentaram modificações morfológicas, já que os valores de número de folhas sadias se mantiveram similares entre os períodos analisados, independente do sistema de cultivo utilizado.

A presença e número de raízes nas plântulas cultivadas in vitro pode influenciar no sucesso de aclimatação. A intensificação da produção de raízes in vitro é frequentemente relacionada ao emprego de reguladores de crescimento como a auxina sintética, o AIB (ácido-indolilbutírico). Porém o uso de reguladores de crescimento no meio de cultivo tem sido associado ao aparecimento de variações somaclonais (Joyce et al. 2003), indesejáveis quando se pretende uma uniformização da produção ou mesmo a manutenção do genótipo original, isento de mutações, visando programas de conservação (Carneiro \& Mansur 2004). Alternativamente ao uso dessas substâncias, tem sido demonstrado que o aumento da concentração de carboidratos, mais frequentemente a sacarose, adicionada ao meio de cultura, pode ser um fator determinante no sucesso da aclimatação, por induzir o desenvolvimento do sistema radicular (Sorace et al. 2008). Plantas da orquídea Oncidium baueri Lindl., cultivadas in vitro, na presença de uma concentração maior de sacarose $\left(40 \mathrm{~g} \mathrm{l}^{-1}\right)$ que a de costume $\left(30 \mathrm{~g} \mathrm{l}^{-1}\right)$, apresentaram melhor crescimento quando transferidas para cultivo em casa de vegetação. Sorace et al. (2008), que trabalharam com essa espécie, associaram o maior desenvolvimento do sistema radicular ao sucesso na aclimatação dessa orquídea. Calvete et al. (2002) observaram que plantas de Fragaria L. (morangueiro) cultivadas in vitro, na ausência de sacarose, não apresentavam enraizamento e que a concentração de $45 \mathrm{~g} \mathrm{l}^{-1}$ foi a mais favorável ao aparecimento de raízes.

A avaliação das plântulas advindas do cultivo in vitro, durante a etapa de aclimatação (Fig. 1g), mostrou que o índice de sobrevivência após dois meses foi de aproximadamente $90 \%$ para todos os períodos de tempo analisados (Tab. 1). Não foram observadas variações morfológicas ou alterações na pigmentação das folhas de todas as plântulas aclimatadas, além disso, independente do tempo de cultivo in vitro as plântulas apresentaram crescimento da parte aérea e das raízes quando cultivadas ex vitro (Tabs. 1 e 2). Entretanto, o crescimento foi mais
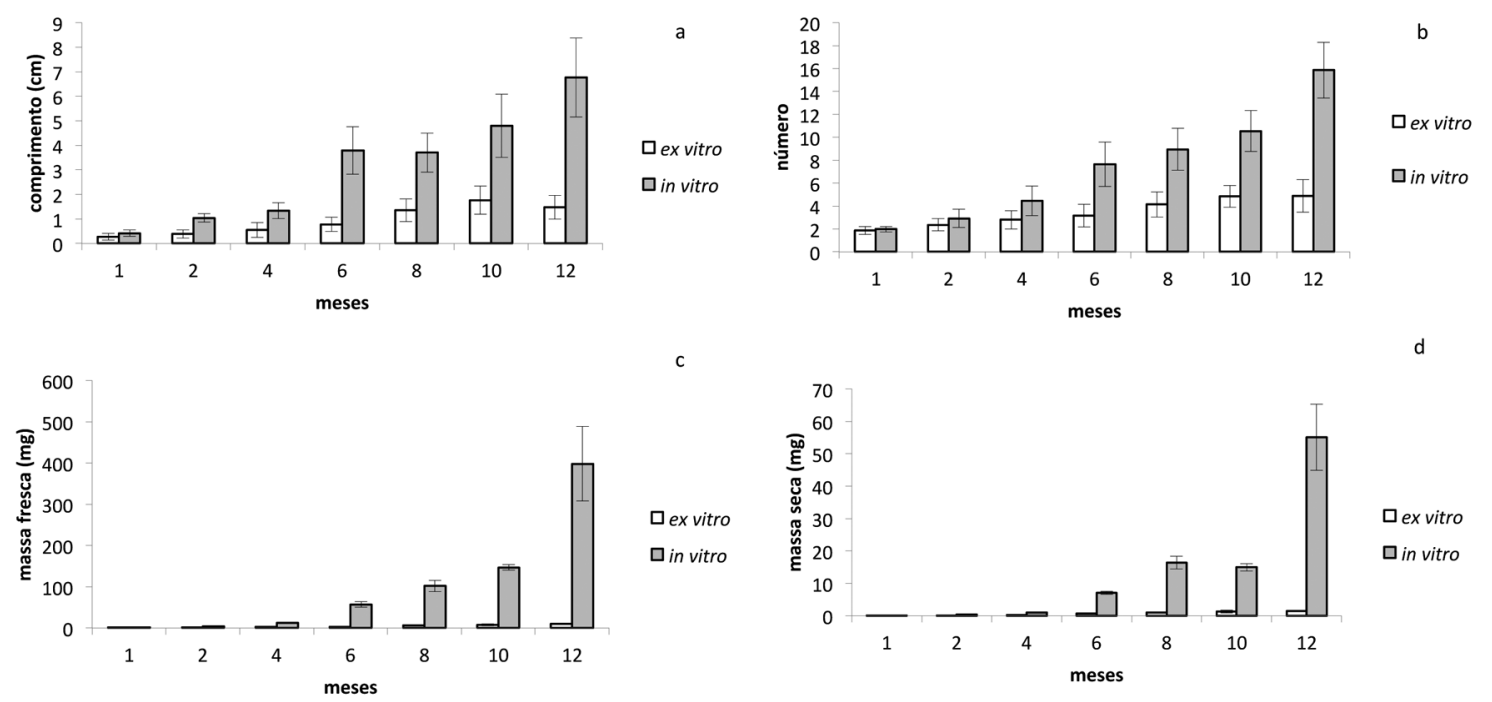

Figura 4-Crescimento das raízes de plantas de Alcantarea imperialis cultivadas in vitro e ex vitro por 1, 2, 4, 6, 8, 10 e 12 meses - a. comprimento (cm); b. número; c. massa fresca (mg); d. massa seca (mg). Os valores representam a média e as barras indicam o desvio padrão $(n=50)$.

Figure 4-Root growth of Alcantarea imperialis cultivated in vitro and ex vitro for 1, 2, 4, 6, 8, 10 and 12 months - a. length (cm); b. number; c. fresh mass (mg); d. dry mass (mg). The values represented the average and the bars indicated the standard deviations $(n=50)$. 
intenso nas plântulas mantidas por 2 meses nas condições in vitro, tanto das raízes como da parte aérea. As plântulas aclimatadas após esse período de cultivo in vitro apresentaram cerca de $500 \%$ de aumento nos valores de massa, fresca e seca, da parte aérea, além de $145 \%$ de incremento nos valores para o comprimento das folhas; contudo, para os dados de número de folhas o aumento foi de apenas $80 \%$ (Tab. 1).

Os dados de massa, fresca e seca, das raízes e da parte aérea aumentaram em todos os períodos após a aclimatação, indicando que mesmo com a senescência de algumas folhas, ocorreu o aumento da biomassa das plântulas. Os dados indicam que o incremento nos valores de massa ocorreu devido ao aumento no comprimento das folhas e não do número delas. Os resultados que mostram o crescimento de plântulas aclimatadas após quatro meses de cultivo in vitro indicam que o ganho de massa foi diminuindo em relação àquelas mantidas por menos tempo nos frascos, tanto para a parte aérea como para as raízes (Tabs. 1 e 2).

Em comparação com outros trabalhos sobre o cultivo in vitro de bromélias foi possível verificar que o tempo de permanência nas condições in vitro varia muito entre as espécies, podendo ser de 2 a 13 meses (Droste et al. 2005; Alves et al. 2006; Silva et al. 2007). Porém, em todos os trabalhos citados anteriormente o objetivo não foi avaliar o menor tempo de cultivo in vitro que propiciasse o desenvolvimento satisfatório das plântulas quando aclimatadas, conforme mostrado neste trabalho para a bromélia-imperial.

Conforme mencionado anteriormente, o tempo necessário para a aclimatação pode diferir conforme a espécie de bromélia, variando de 4 a 6 meses (Pickens et al. 2003; Pompelli \& Guerra 2005; Silveira et al. 2009). Porém o período utilizado com maior frequência foi o de 2 meses citado, para várias espécies (Arrabal et al. 2002; Rech Filho et al. 2005; Alves et al. 2006; Rech Filho et al. 2009), o que corrobora os resultados observados no presente trabalho para $A$. imperialis. Vale ressaltar que dentre os períodos analisados, a aclimatação de plântulas mantidas in vitro por 2 , 4 e 6 meses apresentaram melhor crescimento em comparação àquelas aclimatadas após terem sido cultivadas por mais tempo in vitro, recomendandose, portanto, que as plantas dessa espécie sejam mantidas por no máximo 6 meses na condição in vitro antes de serem submetidas à aclimatação.
O cultivo in vitro se mostrou, assim, eficiente e pode otimizar a produção da bromélia-imperial, constatando-se que plântulas com apenas 2 meses de cultivo in vitro já podem ser aclimatadas, contribuindo para uma diminuição no tempo de cultivo e na importante relação custo-benefício para sua produção comercial.

\section{Referências}

Alves, G.M.; Vesco, L.L.D. \& Guerra, M.P. 2006. Micropropagation of the Brazilian endemic bromeliad Vriesea reitzii trough nodule clusters culture. Scientia Horticulturae 110: 204-207.

Aranda-Peres, A.N. \& Martinelli, A.P. 2009. Adjustment of mineral elements in the culture medium for the micropropagation of three Vriesea bromeliads from the Brazilian Atlantic Forest: the importance of calcium. HortScience 44: 106-112.

Arrabal, R.; Amancio, F.; Carneiro, L.A.; Neves, L.J. \& Mansur, E. 2002. Micropropagation of endangered endemic Brazilian bromeliad Cryptanthus sinuosus (L.B. Smith) for in vitro preservation. Biodiversity and Conservation 11: 1081-1089.

Barbará, T.; Martinelli, G.; Fay, M.F.; Mayo, S.J. \& Lexer, C. 2007. Population differentiation and species cohesion in two closely related plants adapted to neotropical high-altitude 'inselbergs', Alcantarea imperialis and Alcantarea geniculata (Bromeliaceae). Molecular Ecology 16: 19811992.

Barbará, T.; Lexer, C.; Martinelli, G.; Mayo, S.; Fay, M.F. \& Heuertz, M. 2008. Within-population spatial genetic structure in four naturally fragmented species of a neotropical inselberg radiation, Alcantarea imperialis, A geniculata, $A$. glaziouana and $A$. regina (Bromeliaceae). Heredity 101: 285-296.

Barbará, T.; Martinelli, G.; Palma-Silva, C.; Fay, M.F.; Mayo, S. \& Lexer, C. 2009. Genetic relationships and variation in reproductive strategies in four closely related bromeliads adapted to neotropical 'inselbergs': Alcantarea glaziouana, A. regina, A. geniculata and A. imperialis (Bromeliaceae). Annals of Botany 103: 65-77.

Buchanan, B.; Gruissem, W. \& Jones, R. 2002. Biochemistry \& molecular biology of plants. American Society of Plant Physiologists, Rockville. $1377 \mathrm{p}$.

Calvete, E.O.; Kämpf, A.N. \& Suzin, M. 2002. Concentração de sacarose no enraizamento in vitro de morangueiro. Horticultura Brasileira 20: 186-191.

Carneiro, L.A. \& Mansur, E. 2004. Contribuição de metodologias in vitro para a conservação de Bromeliaceae. Vidalia 2: 12-20. 
Debergh, P.C. 1994. In vitro culture of ornamentals. In: Vasil, I.K. \& Thorpe, T.A. (eds.). Plant cell and tissue culture. Kluwer Academic Publishers, Dordrecht. Pp. 561-573.

Debergh, P.C. \& Maene, L.J. 1981. A scheme for commercial propagation of ornamental plants by tissue culture. Scientia Horticulturae 14: 335-345.

Dias, L.A.S. \& Barros, W.S. 2009. Biometria experimental. Suprema, Viçosa. 408p.

Droste, A.; Silva, A.M.; Matos, A.V. \& Almeida, J.W. 2005. In vitro culture of Vriesea gigantea and Vriesea philippocoburgii: two vulnerable bromeliads native to southern Brazil. Brazilian Archives of Biology and Technology 48: 717722.

Engelmann, F. 1991. In vitro conservation of tropical plant germplasm - a review. Euphytica 57: 227-243.

Engelmann, F. 1997. Present development and use of in vitro culture techniques for the conservation of plant genetic resources. Acta Horticulturae 447: 471-475.

Fay, M.F. 1994. In what situations is in vitro culture appropriate to plant conservation? Biodiversity and Conservation 3: 176-183.

Hartmann, H.T.; Kester, D.E.; Davies Jr., F.T. \& Geneve, R.L. 2002. Plant propagation: principles and practices. 7 ed. Upper Saddle River, New Jersey. 770p.

Joyce, S.M.; Cassells, A.C. \& Jain, M. 2003. Stress and aberrant phenotypes in in vitro culture. Plant Cell, Tissue and Organ Culture 74: 103-121.

Kozai, T. 1991. Photoautotrophic micropropagation. In vitro Cellular \& Developmental Biology-Plant 27: 47-51.

Kozai, T.; Kubota, C. \& Jeong, B.R. 1997. Environmental control for the large-scale production of plants through in vitro techniques. Plant Cell, Tissue and Organ Culture 51: 49-56.

Martinelli, G. 1997. Biologia reprodutiva de Bromeliaceae na Reserva Ecológica de Macaé de Cima. In: Lima, H.C. \& Guedes-Bruni, R.R. (eds.). Serra de Macaé de Cima: diversidade florística e conservação em Mata Atlântica. Instituto de Pesquisa Jardim Botânico do Rio de Janeiro, Rio de Janeiro, 213-250.

Melo, T.B. 1996. As bromélias no paisagismo. Bromélia 3: 3-7.

Mercier, H. \& Kerbauy, G.B. 1995. The importance of tissue culture technique for conservation of endangered brazilian bromeliads from Atlantic rain forest canopy. Selbyana 16: 147-149.

Mercier, H. \& Nievola, C.C. 2003. Obtenção de bromélias in vitro como estratégia de preservação. Vidalia 1: 57-62.

MMA - Ministério do Meio Ambiente. 2008. Instrução normativa no. 6 , de 23 de setembro de 2008 .
Monteiro, R.F. \& Forzza, R.C. 2008. A família Bromeliaceae no Parque Estadual do Ibitipoca, Minas Gerais, Brasil. Boletim de Botânica da Universidade de São Paulo 26: 7-33.

Moritz, C. 2002. Strategies to protect biological diversity and the evolutionary processes that sustain it. Systematic Biology 51: 238-254.

Murashige, T. \& Skoog, F. 1962. A revised medium of rapid growth and biossays with tissue cultures. Physiologia Plantarum 15: 473-497.

Pedroso, A.N.V.; Lazarini, R.A.M.; Tamaki, V. \& Nievola, C.C. 2010. In vitro culture at low temperature and ex vitro acclimatization of Vriesea inflata an ornamental bromeliad. Revista Brasileira de Botânica 33: 407-414.

Pence, V. 2011. The possibilities and challenges of in vitro methods for plant conservation. Kew Bulletin 65: 539-547.

Pickens, K.A.; Affolter, J.M. \& Wetztein, H.Y. 2003. Enhanced seed germination and seedling growth of Tillandsia eizii in vitro. HortScience 38: 101104.

Pierik, R.L.M. 1987. In vitro culture of higher plants. Martinus Nijhoff Publishers, Dordrecht. 344p.

Pompelli, M.F. \& Guerra, M.P. 2005. Micropropagation enables the mass propagation and conservation of Dyckia distachya Hassler. Crop Breeding and Applied Biotechnology 5: 117-126.

Rech Filho, A.; Vesco, L.L.D.; Nodari, R.O.; Lischka, R.W.; Muller, C.V. \& Guerra, M.P. 2005. Tissue culture for the conservation and mass propagation of Vriesea reitzii Leme and Costa, a bromeliad threatened of extinction from the Brazilian Atlantic Forest. Biodiversity and Conservation 14: 17991808.

Rech Filho, A.; Vesco, L.L.D. \& Guerra, M.P. 2009. Adventitious shoots from nodule cluster cultures of Vriesea reitzii: an endemic and endangered bromeliad from atlantic forest. Ciência Rural 39: 909-912.

Reuther, G. 1988. Comparative anatomical and physiological studies with ornamental plants under in vitro and greenhouse conditions. Acta Horticulturae 226: 91-98.

Sarasan, V.A.; Cripps, R.; Ramsay, M.M.; Atherton, C.; McMichen, M.; Prendergast, G. \& Rowntree, J.K. 2006. Conservation in vitro of threatened plants - progress in the past decade. In vitro Cellular \& Developmental Biology-Plant 42: 206-214.

Silva, A.L.L.; Dornelles, E.B.; Bisognin, D.A.; Franco, E.T.H. \& Horbach, M.A. 2007. Micropropagation of Dyckia agudensis Irgang \& Sobral - an extinction threatened bromeliad. Iheringia, Série Botânica 62: 39-43.

Silveira, D.G.; Souza, F.V.D.; Pelacani, C.R.; Souza, A.S.; Ledo, C.A.S. \& Santana, J.R.F. 2009. 
Micropropagation and in vitro conservation of Neoglaziovia variegata (Arr. Cam.) Mez, a fiber producing bromeliad from Brazil. Brazilian Archives of Biology and Technology 52: 923932.

Sorace, M.; Faria, R. T.; Damasceno Júnior, C.V.; Gomes, G.P., Barbosa, C.M.; Vieira, F.G.N.; Silva, G.L.; Takahasshi, L.S. A. \& Schnitzer, J. A. 2008. Crescimento in vitro de Oncidium baueri (Orquidaceae) em diferentes concentrações de macronutrientes e sacarose. Semina: Ciências Agrárias 29: 775-782.

Taiz, L. \& Zeiger, E. 2009. Fisiologia vegetal. $4^{\text {th }}$ ed. Armed, Porto Alegre. 820p.

Thorpe, T.A. \& Harry, I.S. 1997. Application of tissue culture to horticulture. Acta Horticulturae 447: 39-49.
Torres, A.C.; Caldas, L.S. \& Buso, J.A. 1998. Cultura de tecidos e transformação genética de plantas. Vols. I e II. EMBRAPA, Brasília. 864p.

Stockwell, C.A.; Hendry, A.P. \& Kinnison, M.T. 2003. Contemporary evolution meets conservation biology. Trends in Ecology \& Evolution 18: 94-101.

Versieux, L.M. 2009. Sistemática, filogenia e morfologia de Alcantarea (Bromeliaceae). Tese de Doutorado. Universidade de São Paulo, São Paulo. 252p.

Versieux, L.M.; Elbl, P.M.; Wanderley, M.G.L. \& Menezes, N.L. 2010. Alcantarea (Bromeliaceae) leaf anatomical characterization and its systematic implications. Nordic Journal of Botany 28: 385-397.

Versieux, L.M. \& Wanderley, M.G.L. 2009. A new species of Alcantarea (Bromeliaceae, Tillandsioideae) from Serra dos Órgãos, Rio de Janeiro, Brazil. Brittonia 61: 336-340. 